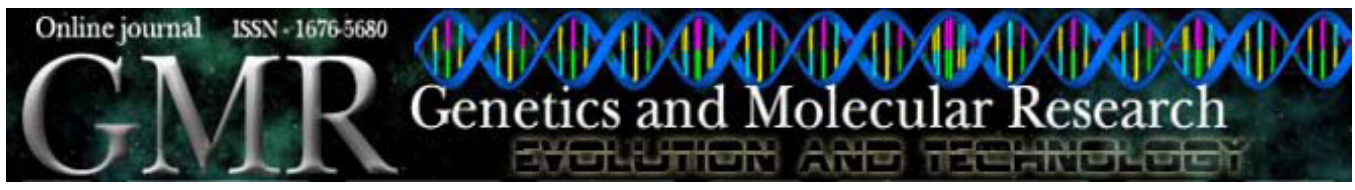

\title{
Cytopathology of Bombyx mori (Lepidoptera: Bombycidae) silk gland caused by multiple nucleopolyhedrovirus
}

\author{
R.M.C. Brancalhão ${ }^{1,2}$, E.F.B. Torquato ${ }^{2}$ and M.A. Fernandez ${ }^{1}$ \\ ${ }^{1}$ Laboratório de Organização Funcional do Núcleo, \\ Departamento de Biologia Celular e Genética, \\ Universidade Estadual de Maringá, Maringá, PR, Brasil \\ ${ }^{2}$ Departamento de Ciências Biológicas e da Saúde, \\ Laboratório de Biologia Celular e Microtécnica, \\ Universidade Estadual do Oeste do Paraná, Cascavel, PR, Brasil \\ Corresponding author: M.A. Fernandez \\ E-mail: aparecidafernandez@gmail.com
}

Genet. Mol. Res. 8 (1): 162-172 (2009)

Received October 27, 2008

Accepted November 28, 2008

Published February 17, 2009

\begin{abstract}
A multiple nucleopolyhedrovirus previously isolated from infected Bombyx mori L. larvae (BmMNPV) in Paraná State, Brazil, was inoculated into B. mori larvae to examine susceptibility and cytopathology in silk gland cells. The anterior, middle and posterior silk glands were removed from the infected silkworm at different times post-inoculation and processed for cytopathology studies by light and transmission electron microscopy. BmMNPV infection was only detected at $72 \mathrm{~h}$ post-inoculation in cells of the middle and posterior silk glands. No sign of infection was found in the anterior silk gland. Cytopathological characteristics were similar to those found in other target tissues; initially, they consisted of nuclear hypertrophy and the formation of virogenic stroma (viroplasm), in which the progeny virions are produced. The virions are then enveloped and occluded in protein crystal structures, the polyhedra. After viral replication, cells undergo lysis and release a great number of BmMNPV polyhedra into the hemocoele. Histopathology showed early infection foci in regions surrounding trachea
\end{abstract}


insertions, demonstrating that trachea is an infection-spreading organ in the insect body. Trachea penetrates the middle and posterior silk gland basal lamina, considered a barrier to virus, facilitating the penetration of budded virus. The anterior silk gland does not have tracheal insertions into the basal lamina, which reduces budded virus infection. Tracheal branches provide a conduit for non-occluded virions (budded virus) to pass through the basal lamina barrier and disseminate BmMNPV in the silkworm silk gland.

Key words: Bombyx mori; Silkworm; Baculoviridae; Trachea; Silk gland; Infection process

\section{INTRODUCTION}

Sericulture is an important agroindustrial activity in Brazil and other developing countries, that includes both Bombyx mori Linnaeus (Lepidoptera: Bombycidae) rearing and mulberry plant cultivation for silkworm nourish. Silkworm cocoons are used by the industry to manufacture various types of silk threads and cloth (Fernandez et al., 2005).

Silkworms are often infected by one of the devastating viral pathogens, Bombyx mori nucleopolyhedrovirus (BmNPV), responsible for grasserie or milky disease. NPV is a genus of the Baculoviridae family that has a single double-stranded circular DNA, which is associated with the capsid proteins, forming the nucleocapsid. The nucleocapsid is enclosed within an envelope. The viral subgroup called single NPV has only one nucleocapsid per envelope; in the case of more than one nucleocapsid, the subgroup is called multiple NPV (MNPV) (Adams and McClintock, 1991; Brancalhão, 2002).

The B. mori nucleopolyhedrovirus type species is single and in many studies it is not identified (Acharya et al., 2002; Rahman and Gopinathan, 2004; Khurad et al., 2005). Brancalhão et al. (2002a) identified a geographic viral isolate belonging to the multiple subgroup, the BmMNPV, in Paraná State. Palhan and Gopinathan (1996) had characterized a geographic viral isolate in Bangalore, India, with indications of being the multiple type. According to the literature, this viral subgroup is more virulent, and there is evidence for geographic viral variability to NPVs of the same species, where this variability could affect virulence (Adams and McClintock, 1991; Hong et al., 2000; Fan et al., 2007).

BmMNPV infects the tegument, tracheae, midgut, fatty tissue, central nervous system, and testis cells (Brancalhão et al., 2002b; Brancalhão and Ribeiro, 2003; Torquato et al., 2006a; Pereira et al., 2008), but there is nothing known about silk gland susceptibility. Some studies showed the susceptibility of B. mori silk gland cells to BmNPV (Rahman and Gopinathan, 2004; Khurad et al., 2005); however, Acharya et al. (2002) reported that the silk gland is not infected by BmNPV. Thus, it is necessary to elucidate the silk gland susceptibility. This organ is responsible for the formation of the cocoon, whose infection will be able to affect silk production, resulting in substantial economic losses to the farmers and industries.

The silk gland pair is a long tubular structure that starts from the labial segment until the caudal region and is morphologically and functionally divided into three distinct regions, the anterior (ASG), middle (MSG) and posterior (PSG). The PSG synthesizes the 
silk fiber protein (fibroin) and MSG synthesizes a group of adhesive proteins that coat the fibroin, the sericins (Goldsmith et al., 2005).

The aim of this study was to determine the susceptibility of $B$. mori larval silk gland cells to the BmMNPV and the ensuing cytopathology, a geographic isolate from Paraná State, Brazil.

\section{MATERIAL AND METHODS}

\section{Insects}

Hybrid larvae of the silkworm B. mori in the 4th instar were obtained from the silk industries of Paraná State, Brazil. These were raised in cardboard boxes until the beginning of pupation, being maintained at $25 \pm 1{ }^{\circ} \mathrm{C}$, with a photoperiod of $14: 10$ (light:dark) and relative humidity of up to approximately $70 \pm 10 \%$, and fed three times a day with fresh leaves of the mulberry tree (Morus sp).

\section{Viruses and inoculation}

Bombyx mori multiple nucleopolyhedrovirus was obtained from hybrid B. mori larvae in Paraná State, Brazil (Brancalhão et al., 2002a). The inoculum viral suspension was prepared by counting the number of viral polyhedra in a Neubauer chamber, at a concentration of $8 \times 10^{7}$ polyhedral occlusion bodies $/ \mathrm{mL}$. In the oral BmMNPV inoculation experiment, the 4th-instar silkworms were fed with virus-free mulberry tree leaves up to ecdysis of the 5th instar. After ecdysis the silkworms were starved for $24 \mathrm{~h}$ and then fed with mulberry leaf disks $\left(2 \mathrm{~cm}^{3}\right.$ in diameter $)$ previously pulverized with $20 \mu \mathrm{L}$ of viral suspension.

The inoculation experiment was performed twice, using 50 silkworms per repetition: 25 silkworms were fed on leaf disks with viral suspension, and 25 on control leaf disks. During feeding, silkworms were individually confined in plastic cups until total consumption of the leaf disks.

Silkworms were placed in labeled cardboard boxes when feeding was complete and then transferred to a controlled room where they remained until the end of the experiment receiving BmMNPV-free mulberry tree leaves.

\section{Microscopic preparations of $B$. mori silk glands}

BmMNPV-infected silkworms were dissected at different hours post-inoculation (hpi) with BmMNPV, starting at 48 and up to 216 hpi, with 24-h intervals. Four silkworms of each group were anesthetized with ethyl ether on dorsal position; a longitudinal opening of the tegument was made from the anal region up to the head. The intestine was removed, making it possible to better expose the silk glands. The regions of the silk glands, ASG, MSG and PSG, were individualized and fixed with DuBosq Brazil (Junqueira and Junqueira, 1983) for $24 \mathrm{~h}$ at $4^{\circ} \mathrm{C}$, for light microscopy. Silk gland regions were washed in $70 \%$ alcohol following routine histological technique for paraffin embedding. Sequential cuts were made with a thickness of $5 \mu \mathrm{m}$, and the cytopathology and histopathology of BmMNPV infections were analyzed with hematoxylin-eosin staining (Junqueira and Junqueira, 1983) and modified Azan staining (Hamm, 1966; Brancalhão et al., 2000) for occlusion bodies. 
For transmission electron microscopy, the silk gland regions were fixed in modified Karnovsky solution (Karnovsky, 1965), for $2 \mathrm{~h}$ at $4^{\circ} \mathrm{C}$. Afterward, they were washed with $0.05 \mathrm{M}$ sodium cacodylate buffer (three times for 10 min each) and post-fixed in 1\% osmium tetroxide for $2 \mathrm{~h}$. The samples were washed in distilled water (two times for $15 \mathrm{~s}$ each) and immersed in $0.5 \%$ uranyl acetate overnight at $4^{\circ} \mathrm{C}$. Subsequently, the material was dehydrated in acetone and infiltrated in Spurr resin (Spurr, 1969): 1:1 mixture Spurr/acetone for 3 h; 1:3 mixture Spurr/acetone for $3 \mathrm{~h}$; pure Spurr resin overnight. Extra thin sections (60-80 nm thickness) were stained with $2 \%$ uranyl acetate $(10 \mathrm{~min})$ and lead citrate $(10 \mathrm{~min})$. Examination and photographic documentation of the material were carried out by transmission electron microscopy (EM 900 ZEISS). Control silkworms were processed as for the BmMNPV-inoculated material.

\section{RESULTS AND DISCUSSION}

The results revealed differences in susceptibility of the silk gland regions of hybrid B. mori larvae to the geographic isolate of BmMNPV. The MSG and PSG regions showed the first signs of infection at $96 \mathrm{hpi}$, while the ASG did not reveal any sign of infection. Figure $1 \mathrm{~A}$ and B shows the MSG infection at $96 \mathrm{hpi}$, and Figure 2A and B at $144 \mathrm{hpi}$, with the cell nucleus full of polyhedra, which causes a pronounced nuclear hypertrophy.

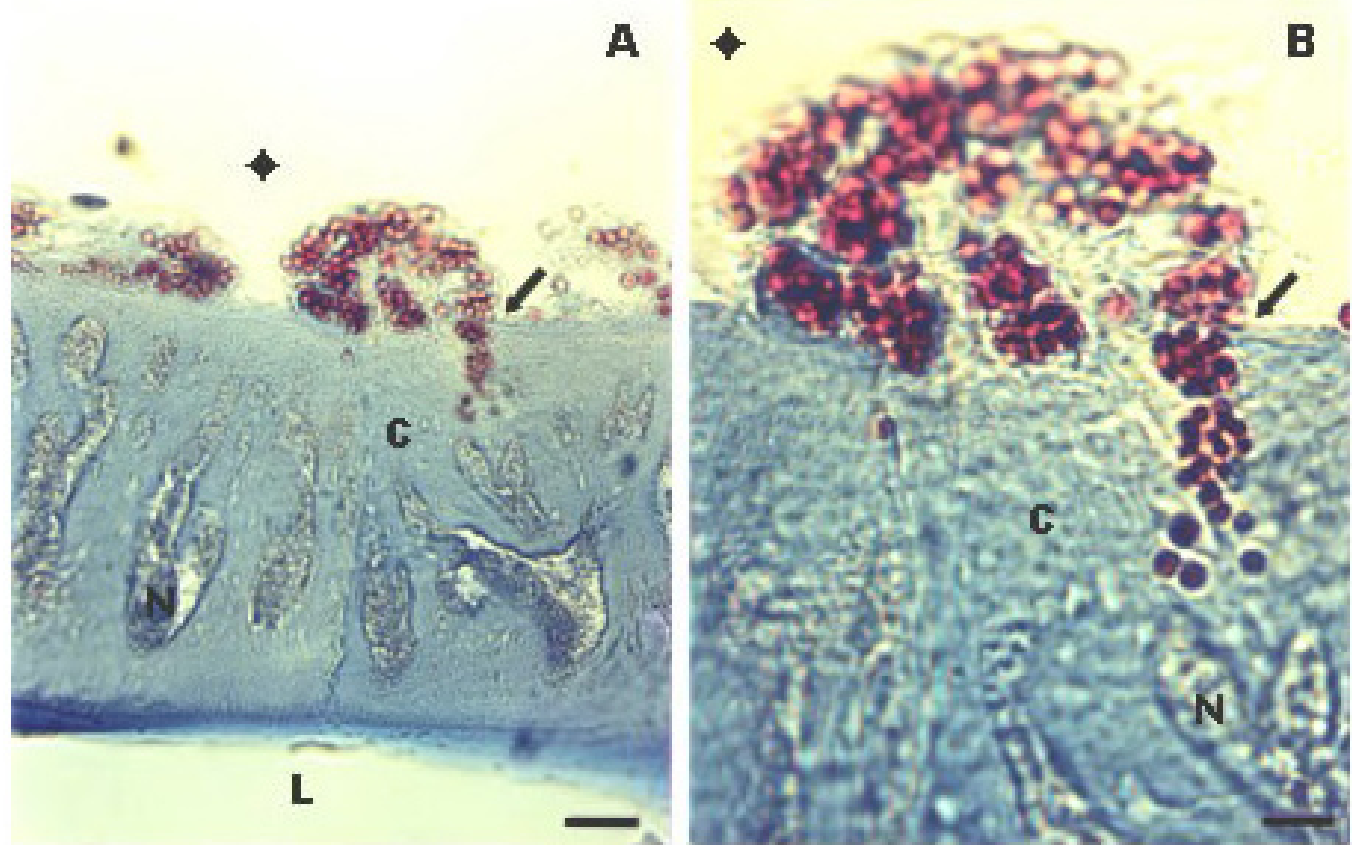

Figure 1. Middle silk gland of 5th-instar Bombyx mori larvae at 96 hours post-inoculation with $B$. mori multiple nucleopolyhedrovirus (BmMNPV). A. BmMNPV penetration through tracheal system (black arrow) in the silk gland epithelium. B. Details of penetration of tracheal branches. Polyhedra in red; N, nucleus; C, cytoplasm; L, lumen of silk gland and extracellular medium ( $\uparrow$. Bar: $25 \mu \mathrm{m}$. Modified Azan stained. Cross cut. Bar: $10 \mu \mathrm{m}$. 


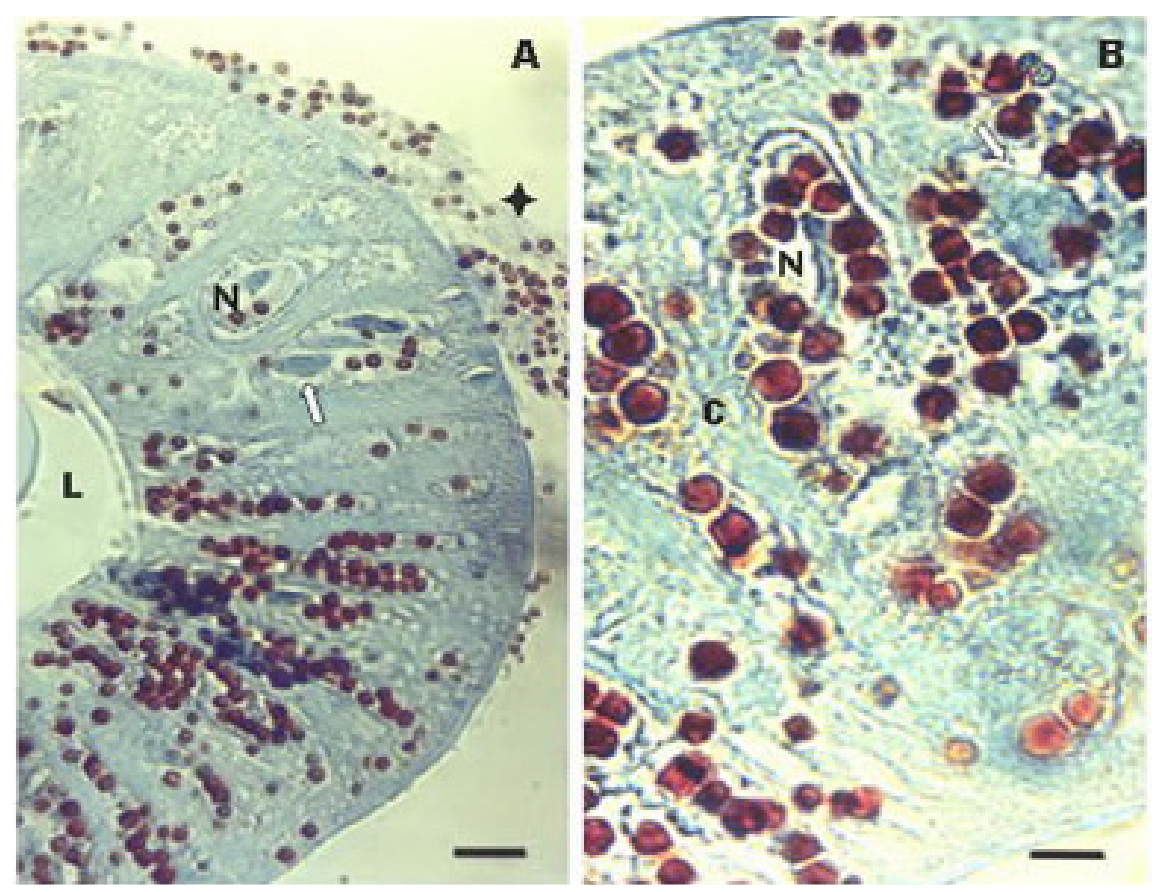

Figure 2. Middle silk gland of 5th-instar Bombyx mori larvae at 144 hours post-inoculation with $B$. mori multiple nucleopolyhedrovirus. A. Infected silk gland epithelium showing viroplasm (white arrow) in the hypertrophic nucleus $(\mathrm{N})$. B. Details of silk gland infection and polyhedron localization inside the cell. Polyhedra in red; C, cytoplasm; L, lumen, and extracellular medium ( $\uparrow$ ). Bar: $25 \mu \mathrm{m}$. Modified Azan stained. Cross cut. Bar: $10 \mu \mathrm{m}$.

Khurad et al. (2005) obtained the same hpi for the MSG of the BmNPV-inoculated silkworm, while finding signs of infection in the PSG only at 168 hpi. Rahman and Gopinathan (2004), using a recombinant virus, demonstrated the infection of the MSG at 72 hpi and no infections in the ASG, as observed in our study for ASG (data not shown). This difference in the infection times is characteristic of NPV infections. They actually occur owing to such factors as the isolate's virulence, amount of ingested virus, larval instar, incidence of other pathogens, and ambient rearing conditions, mainly temperature, population density, and food availability (Adams and McClintock, 1991; Torquato et al., 2006a). We also need to consider the strains of B. mori larvae, which can show a remarkable difference regarding resistance to BmNPV (Ponnuvel et al., 2003; Yao et al., 2003; Nakazawa et al., 2004). This resistance is controlled by a polygenesis effect, which argues the existence of several defenses against viral infection such as proteases and lipases found in silkworm gut juice (Ponnuvel et al., 2003; Nakazawa et al., 2004). It could explain the results of Acharya et al. (2002), referring to no infection of the silk gland.

The cytopathology of BmMNPV infections are similar to those in other target tissues (Brancalhão et al., 2002b, Brancalhão and Ribeiro, 2003; Torquato et al., 2006a; Pereira et al., 2008). In the infected cells, the nucleus initially appears as an electron dense virogenic stroma (viroplasm), where the nucleocapsids are produced (Figure 3A). They then acquire an envelope originated by de novo morphogenesis from the membrane of microvesicles in the infected 
cell nucleus (Figure 3B), forming enveloped nucleocapsids or virions. The virions are enveloped singly or in groups, and the number of nucleocapsids per envelope is variable, 11 being the maximum number for this virus. The occurrence of a variable number of nucleocapsids per envelope is a diagnostic characteristic for MNPVs.

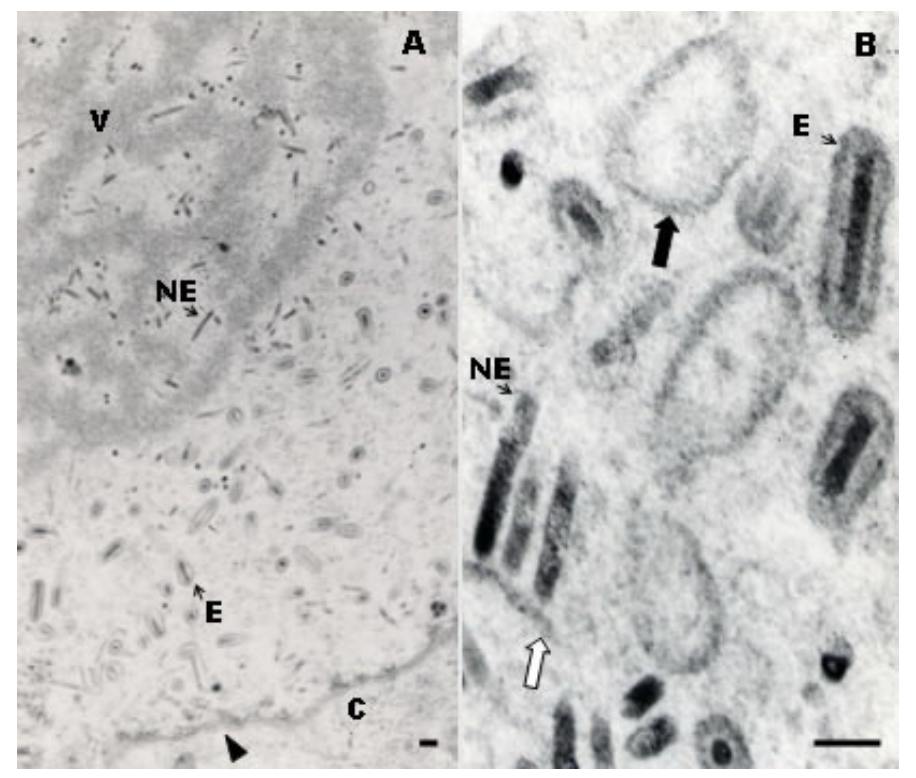

Figure 3. Electron micrographs of the middle silk gland cells of 5th-instar Bombyx mori at 144 hours postinoculation with B. mori multiple nucleopolyhedrovirus. A. Segment of nucleus with viroplasm (V), several nonenveloped nucleocapsids (NE) mainly inside the viroplasm and enveloped nucleocapsids (E) outside; nuclear envelope (arrowhead) and cytoplasm (C). B. Section of non-enveloped nucleocapsids, which is attached to viral envelope (white arrow), enveloped nucleocapsids and membrane microvesicles (black arrow) Bar: $0.1 \mu \mathrm{m}$.

Virions production is followed by the development of polyhedra. Virions are grouped concentrically around a polyhedron-constituted protein matrix (polyhedrin) that crystallizes around virions (Figure 4A). For a better understanding of the polyhedron development process that occurs between viroplasm and the nuclear envelope, they were classified as immature (Figure 4A-D) and mature (Figure 5) (Adams and McClintock, 1991). The immature polyhedron is small without its thin electron-dense coated envelope, and therefore of indefinite geometric shape (Figure 4A-D). The mature bigger polyhedron is present in the nucleus or extracellular medium and has an envelope, which confers its defined geometric shape (Figure 5). The polyhedron envelope or "calyx" seems to have two roles: to prevent the loss of virions, and to avoid polyhedron aggregation (Gross et al., 1994). In the electron micrographs, the polyhedron envelope has a membrane-like structure, as shown in Figure 6. The BmMNPV polyhedron ranges from 2.5 to $4.5 \mu \mathrm{m}$ in diameter and has a truncated octahedron geometric shape (Torquato et al., 2006b). Hong et al. (2000) suggest the existence of genetic variation in the polyhedron geometric shape of BmNPV and that this is specific for each viral lineage. Katsuma et al. (1999) found variations in the shape of polyhedron of the BmNPV caused by polyedrin mutations. 


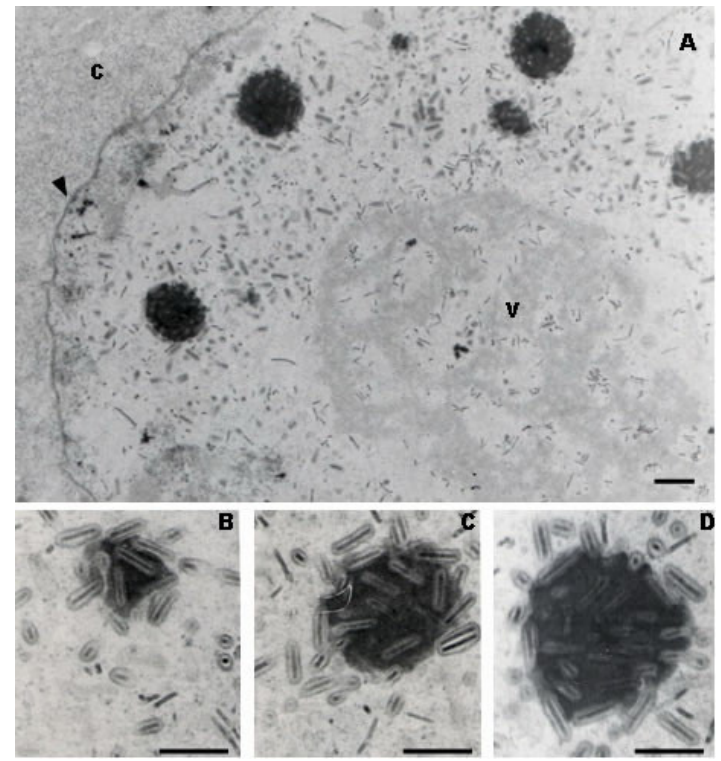

Figure 4. Electron micrographs of the posterior silk gland cells of 5th-instar Bombyx mori at 168 hours postinoculation with B. mori multiple nucleopolyhedrovirus (BmMNPV). A. Segment of nucleus showing BmMNPV polyhedron formation without their envelope. Viroplasm (V), nuclear envelope (arrowhead) and cytoplasm (C). Bar: $1 \mu \mathrm{m}$. B. C. and D. Details of BmMNPV polyhedron formation, where some enveloped nucleocapsids are within the polyhedrin matrix (electron dense mass) while others are just becoming occluded. Bar: $0.5 \mu \mathrm{m}$.

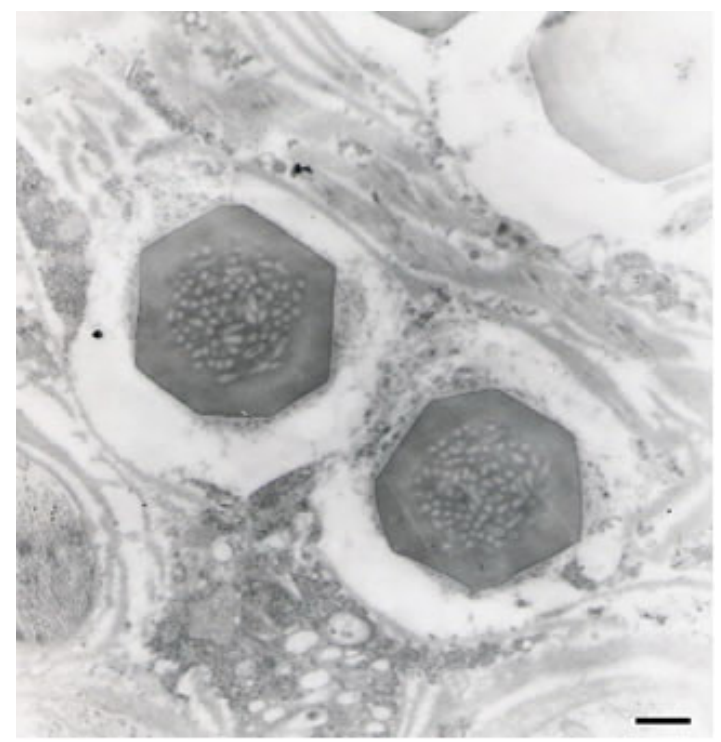

Figure 5. Electron micrography of two mature polyhedra in extracellular medium of 5th-instar Bombyx mori at 168 hours post-inoculation with $B$. mori multiple nucleopolyhedrovirus. The polyhedra are enveloped nucleocapsids within the protein matrix. Bar: $1 \mu \mathrm{m}$. 


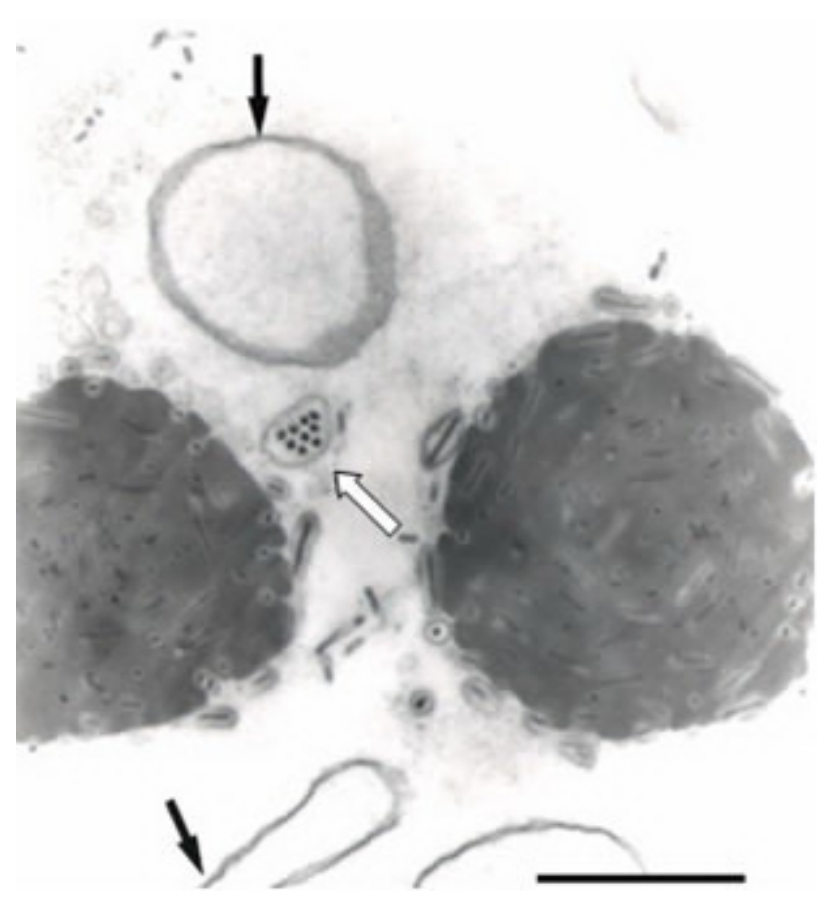

Figure 6. Electron micrography of polyhedron envelope (black arrows) and two immature polyhedra in the nucleus of silk gland cell of 5th-instar Bombyx mori at 168 hours post-inoculation with B. mori multiple nucleopolyhedrovirus. Enveloped nucleocapsids are within the polyhedrin matrix and white arrow shows nine nucleocapsids within an envelope. Bar: $1 \mu \mathrm{m}$.

Variations in the polyhedron's amount and size have been reported in the infected nucleus cells, polyhedron size being inversely proportional to its amount. These variations are frequent in NPV infections, and may be related to the number of occluded nucleocapsids, stage of polyhedron development, metabolism of the infected cell, and virus' genetic variation (Adams and McClintok, 1991). Moreover, the positions occupied by polyhedra in the infected nucleus must be considered, which cause different angulations in histological cuttings (Torquato et al., 2006a,b).

Mature polyhedra are released into the extracellular medium from infected gland cells, which are often lysed. The viral p10 protein, present in the polyhedral matrix, is involved in the nuclear and cell lysis (Hong et al., 2000).

Polyhedra are resistant structures that protect virions from inactivation by adverse environmental conditions. Thus, in the horizontal transmission of the disease, it is important that the polyhedron escapes efficiently from its host. Ohkawa et al. (1994) showed that in the BmNPV genome there is a cathepsin expressed in the late phase of infection, which is responsible for the liquefaction of the insect body. Daimon et al. (2006) reported that in the genome of the $\mathrm{BmNPV}$, there is a chitinase which, together with the cathepsin enzyme, would be responsible for insect cuticle rupture, releasing polyhedra from the insect body to the environment. 
Diseased larvae are a potential virus focus and may produce $1 \times 10^{9}$ polyhedra (Adams and McClintock, 1991). As the virus exhibits high virulence, may retain its pathogenicity in the dead larvae, and persist in the silkworm rearing rooms, prevention and control are very important in preventing viral transmission. Thus, when the silkworm farms detect diseased larvae, they should be removed carefully without breaking the skin and discontinue the use of rearing residues (mulberry leaves and stems) as fertilizer in mulberry tree plantation. Otherwise, the virus may persist in soil from one period to another (Brancalhão et al., 2002a), to reach and to adhere to mulberry leaves, which cycle the virus back to the silkworm in the next generation.

Silk gland MSG and PSG are very active regions, and for this reason, there is a rich aeration provided for tracheal branches. These branches are observed in the periphery and inside the silk gland epithelium. The trachea arrives at the basal surface of the cells and their branches penetrate deeply into the cellular cytoplasm (Figure 1A and B) and intercellular spaces. In the ASG region, tracheal branches are observed only at the periphery. Akai et al. (1993) also reported the smaller frequency of the tracheal system in the ASG and even its absence. In our study, the tracheal tissue associated with the silk gland is BmMNPV-infected at $72 \mathrm{hpi}$.

The trachea accounts for general dispersion of the viral infection in the insect body (Rahman and Gopinathan, 2004). However, other reports confer this role to the hemolymph (Barrett et al., 1998). On the contrary, Soares and Ribeiro (2005) hypothesize that both hemocytes and tracheal cells spread NPV infection in Anticarsia gemmatalis larvae.

During the NPV infectious process, there are two viral phenotypes. One form is occluded within polyhedra and responsible for primary infection in midgut cells. The second form of the virus, called budded virus (BV), never becomes occluded, is released into the hemolymph and spreads infection from cell to cell within insect body (Haas-Stapleton et al., 2005). The start of the replication of the BV is believed to occur in the cells by endocytosis (Herniou et al., 2003). However, the silk gland as well as the majority of insect tissues has a fibrous extracellular matrix, the basal lamina (BL). Therefore, BV needs to penetrate the BL to achieve systemic infection. Studies have shown that BL organization and thickness seem to influence the passage of macromolecules into certain tissues, where it is able to act as a selective filter (Rahman and Gopinathan, 2004). Reddy and Locke (1990) investigated the behavior of gold particles on the BL of Calpodes ethlius (Lepidoptera: Hesperiidae) larvae, and showed that particles smaller than $15 \mathrm{~nm}$ crossed the BL of certain tissues, such as fatty, epidermal and pericardial ones, whereas particles larger than $6 \mathrm{~nm}$ were retained in the silk gland, in the Malpighian tubule and in the muscle BL. BmMNPV virions have an approximate mean diameter of $95 \mathrm{~nm}$ and length of $315 \mathrm{~nm}$ (Torquato et al., 2006b), making the passage of BV through the silk gland BL difficult.

Histopathology of silk gland due to BmMNPV showed that infection is always initiated in the regions surrounding tracheal insertions (Figure 1A and B). The trachea penetrates the MSG and PSG regions by crossing the BL, and as commented above, infection originates from this organ. BVs from tracheal cells reach the silk gland cytoplasm and in the nucleus of these cells establish a new reproductive cycle until the formation of the polyhedra. The role of the tracheal system as an infection-spreading organ was described previously for larval nucleopolyhedrovirus infection (Rahman and Gopinathan, 2004; Torquato et al., 2006a; Pereira et al., 2008).

In conclusion, this study shows that the MSG and PSG regions of the B. mori silk gland are infected with BmMNPV and that the tracheal system is an important conduit for virus spread in the larva. 


\section{ACKNOWLEDGMENTS}

The authors thank the silk companies of the Paraná State for providing the Bombyx mori hybrid larvae, and the Electronic Microscopy Center of the Escola Superior de Agricultura Luis de Queiroz/USP at Piracicaba, SP, Brazil. Research supported by grants from Secretaria de Estado da Ciência, Tecnologia e Ensino Superior, SETI, FUNDO PARANÁ, Fundação Araucária, Santander-Banespa Prize for Science and Innovation 2006, and COMCAP/UEM laboratory facilities.

\section{REFERENCES}

Acharya A, Sriram S, Sehrawat S, Rahman M, et al. (2002). Bombyx mori nucleopolyhedrovirus: molecular biology and biotechnological applications for large-scale synthesis of recombinant proteins. Curr. Sci. 83: 455-465.

Adams JR and McClintock JT (1991). Baculoviridae. Nuclear Polyhedrosis Viruses. Part 1. Nuclear Polyhedrosis Viruses of Insects. In: Atlas of Invertebrate Viruses (Adams JR and Bonami JR, eds.). CRC Press, Florida, 89-180.

Akai H, Nagashima T and Aoyagi S (1993). Ultrastructure of posterior silk gland cells and liquid silk in Indian tasar silkworm, Antheraea mylitta Drury (Lepidoptera: Saturniidae). Int. J. Insect Morphol. Embryol. 22: 497-506.

Barrett JW, Brownwright AJ, Primavera MJ and Palli SR (1998). Studies of the nucleopolyhedrovirus infection process in insects by using the green fluorescence protein as a reporter. J. Virol. 72: 3377-3382.

Brancalhão RMC (2002). Vírus entomopatogênico no bicho-da-seda: Taxonomia e citopatologia causada por nucleopolyhedrovirus em células de Bombyx mori. Biotecnol. Cienc. Desenvolv. 24: 54-58.

Brancalhão RMC and Ribeiro LFC (2003). Cytopathology of BmNPV infection in the integument of Bombix mori L., 1758 (Lepidoptera: Bombicidae). Arq. Ciên. Vet. Zool. 6: 15-20.

Brancalhão RMC, Souza VBV and Fortes JC (2000). A simplified methodology to detect nucleopolyhedrovirus in Bombyx mori L., 1758 (Lepidoptera: Bombycidae). Arq. Inst. Biol. 67: 89-92.

Brancalhão RMC, Torquato EFB and Castro MEB (2002a). Identification of a Bombyx mori multiple nucleopolyhedrovirus isolate (BmMNPV) in Paraná State, Brazil. Embrapa Bol. Pesq. Desenvol. 33: 5-12.

Brancalhão RMC, Souza VBV and Soares MAM (2002b). Infecção causada por NPV nas células gordurosas de Bombyx mori L., 1758 (Lepidoptera: Bombycidae). Arq. Inst. Biol. 69: 57-63.

Daimon T, Katsuma S, Kang W and Shimada T (2006). Comparative studies of Bombyx mori nucleopolyhedrovirus chitinase and its host ortholog, BmChi-h. Biochem. Biophys. Res. Commun. 345: 825-833.

Fan Q, Li S, Wang L, Zhang B, et al. (2007). The genome sequence of the multinucleocapsid nucleopolyhedrovirus of the Chinese oak silkworm Antheraea pernyi. Virology 366: 304-315.

Fernandez MA, Ciferri RR, Patussi EV, Pereira MF, et al. (2005). A utilização da biotecnologia na sericicultura brasileira. Biotec. Cienc. Desenvolv. 35: 56-61.

Goldsmith MR, Shimada T and Abe H (2005). The genetics and genomics of the silkworm, Bombyx mori. Annu. Rev. Entomol. 50: 71-100.

Gross CH, Russell RL and Rohrmann GF (1994). Orgyia pseudotsugata baculovirus p10 and polyhedron envelope protein genes: analysis of their relative expression levels and role in polyhedron structure. J. Gen. Virol. 75 (Pt 5): 1115-1123.

Haas-Stapleton EJ, Washburn JO and Volkman LE (2005). Spodoptera frugiperda resistance to oral infection by Autographa californica multiple nucleopolyhedrovirus linked to aberrant occlusion-derived virus binding in the midgut. J. Gen. Virol. 86: 1349-1355.

Hamm JJ (1966). A modified azan staining technique for inclusion body viruses. J. Invertebr. Pathol. 8: 125-126.

Herniou EA, Olszewski JA, Cory JS and O'Reilly DR (2003). The genome sequence and evolution of baculoviruses. Annu. Rev. Entomol. 48: 211-234.

Hong HK, Woo SD, Choi JY, Lee HK, et al. (2000). Characterization of four isolates of Bombyx mori nucleopolyhedrovirus. Arch. Virol. 145: 2351-2361.

Junqueira LC and Junqueira LMMS (1983). Técnicas Básicas de Citologia e Histologia. Livraria e Editora Santos, São Paulo.

Karnovsky MJ (1965). A formaldehyde-glutaraldehyde fixative of high osmolarity for use in electron microscopy. J. Cell Biol. 27: 137-138.

Katsuma S, Noguchi Y, Shimada T, Nagata M, et al. (1999). Molecular characterization of baculovirus Bombyx mori nucleopolyhedrovirus polyhedron mutants. Arch. Virol. 144: 1275-1285.

Genetics and Molecular Research 8 (1): 162-172 (2009)

CFUNPEC-RP www.funpecrp.com.br 
Khurad AM, Mahulikar A, Rathod MK and Rai MM (2005). Infection of nucleopolyhedrovirus in the larval rudiments of gonads of silkworm, Bombyx mori L. Indian J. Seric. 44: 159-164.

Nakazawa H, Tsuneishi E, Ponnuvel KM, Furukawa S, et al. (2004). Antiviral activity of a serine protease from the digestive juice of Bombyx mori larvae against nucleopolyhedrovirus. Virology 321: 154-162.

Ohkawa T, Majima K and Maeda S (1994). A cysteine protease encoded by the baculovirus Bombyx mori nuclear polyhedrosis virus. J. Virol. 68: 6619-6625.

Palhan VB and Gopinathan KP (1996). Characterization of the local isolate of Bombyx mori nuclear polyhedrosis virus. Curr. Sci. 70: 147-153.

Pereira EP, Conte H, Ribeiro LF, Zanatta DB, et al. (2008). Cytopathological process by multiple nucleopolyhedrovirus in the testis of Bombyx mori L., 1758 (Lepidoptera: Bombycidae). J. Invertebr. Pathol. 99: 1-7.

Ponnuvel KM, Nakazawa H, Furukawa S, Asaoka A, et al. (2003). A lipase isolated from the silkworm Bombyx mori shows antiviral activity against nucleopolyhedrovirus. J. Virol. 77: 10725-10729.

Rahman MM and Gopinathan KP (2004). Systemic and in vitro infection process of Bombyx mori nucleopolyhedrovirus. Virus Res. 101: 109-118.

Reddy JT and Locke M (1990). The size limited penetration of gold particles through insect basal lamina. J. Insect Physiol. 36: 397-407.

Soares JS and Ribeiro BM (2005). Pathology of Anticarsia gemmatalis larvae infected by two recombinant $A$. gemmatalis multicapsid nucleopolyhedroviruses. Res. Microbiol. 156: 263-269.

Spurr AR (1969). A low-viscosity epoxy resin embedding medium for electron microscopy. J. Ultrastruct. Res. 26: 31-43.

Torquato EF, Neto MH and Brancalhão RM (2006a). Nucleopolyhedrovirus infected central nervous system cells of Bombyx mori (L.) (Lepidoptera: Bombycidae). Neotrop. Entomol. 35: 70-74.

Torquato EF, de Miranda Neto MH, Brancalhão RM and Franco VS (2006b). Nucleopolyhedrovirus: scanning electron microscopy technique. Neotrop. Entomol. 35: 787-790.

Yao Q, Li MW, Wang Y, Wang WB, et al. (2003). Screening of molecular markers for NPV resistance in Bombyx mori L. (Lep., Bombycidae). J. Appl. Entomol. 127: 134-136. 